\title{
Historical and Epidemiological Aspects of Some Human Diseases Just to Zika Virus, a Short Review
}

\author{
Rachel Siqueira de Queiroz Simões ${ }^{1 *}$ \& Ortrud Monika Barth ${ }^{1}$ \\ ${ }^{1}$ Laboratory of Morphology and Viral Morphogenesis, Instituto Oswaldo Cruz, Fundação Oswaldo \\ Cruz, Avenida Brasil 4365, Manguinhos, Rio de Janeiro, RJ, Brazil. \\ *rachel.simoes@ioc.fiocruz.br; *rachelsqsimoes@gmail.com.
}

\begin{abstract}
Currently there are several branches of epidemiology that can be exemplified as the clinical epidemiology of infectious and non-infectious diseases applying epidemiological issues related to diagnosis, prognosis and therapeutic principles. Methodological and scientific evidence as to epidemics and pandemics today underlie the hypothetical studies that were previously only in the early empirical assumptions given the lack of a more refined knowledge. The article makes an analytical approach as the distribution of diseases over time the historical point of view making a crossing of infectious diseases to chronic diseases in epidemiological transition presents nowadays.
\end{abstract}

Keywords: epidemiology, epidemics, history, public health.

\section{INTRODUCTION}

To discuss the epidemiological screening based on methodological issues should take into account the chronology of the natural history of the disease. The effectiveness of screening programs is evaluated using operational measures and clinical outcome measures. The natural history of the disease can be short or long depending upon the relationship between the duration of the clinical and pre-clinical stages. The goal of screening is to detect the disease in preclinical phase before the onset of clinical symptoms (Gordis 2010).

Historically, the origin of epidemiology was born with the observations of Hippocrates, there are more than 2,000 years ago, analyzing the occurrence of diseases associated with environmental factors. The etymology of the word epidemiology comes from Greek: Epi (on), demio (people, population) and logos (study, knowledge) (Last, 1988, Bonita et al. 2010).

Conceptually, it defines epidemiology as a basic science that studies the distribution of diseases and their causes in human populations in order to prevent, or the study of the factors that determine the frequency and distribution of diseases in human communities, or, study of distribution and events of health related in specific populations, and the application of this study in the control of health-related problems (Last 1988).

An epidemiological study can be applied in the development and evaluation of public policies in social areas and laboratory research. Epidemiological triad of diseases consists of the interrelationship between the agent, the host and the environment (Gordis 2010). Biological, chemical, physical and nutritional agents must be considered among the etiological factors. Some host factors were influenced by exposure and susceptibility or the response to agents such as age, sex, marital status, occupation, education, genetic characteristics and the immune status. There are environmental factors that influence the existence of an agent, its susceptibility and contact with the host, such as physical and chemical determinants (temperature, humidity, pollution, accidents), biological determinants (accidents, infections) and social determinants (behavior, social organization) (Gordis 2010).

The distribution of diseases study in space and time can be measured by the analysis of geographic maps or by the mapping of specifics diseases in time specific. There are three basic pillars relating to spatial and temporal issues: (i) who falls ill? Referring to the subject as a person; (ii) where it is? By mentioning the space; (iii) when there? Related to the time period of occurrence of the disease (Medronho 2009). These maps have been used since XVIII by James Lind to measured the escoburt 
disease. Until the date, others mappings have been used in the medical investigation as also in the juridical practice in the crimes cases (Medronho 2009).

The present article reports about epidemiological screening and history aspects of some human viral diseases as papillomavirus, smallpoxvirus, ebolavirus, zikavirus and some other arboviruses beside cholera and puerperal fever.

\section{Papillomavirus disease}

The natural history of the disease presents specific measures of three levels of prevention: (i) primary (screening), (ii) secondary (therapy) and (iii) tertiary (immunization). The economic impact of costeffectiveness of vaccination estimated the prevention of the new cases of cervical cancer associated with oncogenic HPV types, and a decrease in the incidence of genital wart in the next 100 years (Kavanagh et al, 2013, Panatto et al, 2013, Uuskula et al, 2013).

Several studies have registered the impact of the epidemiological screening of human papillomavirus (HPV). The most commonly used epidemiological design is a cross-sectional study using different clinical specimens as urine, cytology samples, swabs of self-collection (Kavanagh et al, 2013). Multiple infections of HPV, prevalence of the high-risk types and cofactors for the persistence of viral infection have been documented in many studies (Panatto et al. 2013, Agyri et al. 2013, Clarke et al. 2012, Figueiredo Alves et al. 2013). Populations studies involving sexually active women of the many countries have been detected the HPV-16 by different methodologies to amplification of ORF L1 HPV (Panatto et al. 2013, Agyri et al. 2013, Pereira et al. 2007).

A recombinant DNA technology has allowed the development of prophylactic vaccines for HPV using different expression systems: (i) bivalent vaccine against HPV types 16 and 18; (ii) quadrivalent vaccine composed of antigen types $6,11,16$ and 18 and (iii) recombinant nonavalente vaccine for preventing tumors associated with HPV (cervical cancers, vulva, vagina and anal cancer) caused by HPV types 16, 18, 31, 33, 45, 52 and 58, and to prevent genital warts caused by HPV types 6 or 11, including another tumors like head and neck, and colorectal tumors. There is the promise of a therapeutic vaccine with new therapeutic targets (Simões \& Barth, 2015).

\section{SMALlPOXVIRUS DISEASE}

In the late eighteenth century, about 400,000 people died of smallpox per year and one third of survivors showed blinding sequelae. The variolization designated the practice of infecting healthy individuals with material from smallpox patients, since the survivors were immune. However, this procedure resulted in many deaths and the development of numerous infections such as syphilis and hepatitis (Miranda 2002).

Edward Jenner, interested in studying the disease, began his observational research in which recorded that in cow milking at that time commonly women, developed a lesion called cowpox causing hand injuries only. His hypothesis tested that the cowpox virus could be protecting the infected women against human smallpox. And it was from these observational data, which in 1796 was the first vaccination derivative of the smallpox pustule inoculated in an eight-year-old child named James Phipps. It has developed only one lesion at the inoculation site regressing in two weeks. A new inoculation was made at the same boy with samples of smallpox lesions of infected people and showed no symptoms of the disease (Gordis 2010).

Jenner was considered a fraud and persecuted by religious fundamentals after his description through the material obtained of the animals injuries that would be to prevent smallpox to millions of people. Consequently his manuscript for publication of the vaccine was refused (Schatzmayr \& Cabral 2012). In parallel, at the same time in 1791, Professor Peter Plett in Germany, recorded very similar experiences to those described in the work of Jenner.

After Jenner's death in 1823, vaccination was already widespread and accepted by all countries, including England and the United States. However in the year 1774 Benjamin Just described the immunization of his family with the fluid of vesicular lesions. The great fear was that many of the vaccinated cases are seriously following the practice of variolization (Schatzmayr \& Cabral 2012).

In 1811, the deployment of smallpox vaccination in Brazil, but specifically in the city of Rio de Janeiro was marked by the first action of public health after the creation of Vaccinia Board of the Court, which gained momentum with the introduction of the Code of Postures in 1832 making 
obligatory the vaccination for every child after three months of birth. Such an act of obligation was strengthened in 1903 by researcher Oswaldo Cruz causing much controversy at the time, since outbreaks of the disease resurfaced in the 1850s even after the creation called Vaccinium Institute of the Empire, as documented by Schatzmayr \& Cabral 2012.

In the nineteenth century, the practice of vaccination began to be disseminated by European countries and other countries as China, India, Persia and Africa where, the immunization occurred against smallpox. The researchers Prowazek and Aragão in Brazil demonstrated that the viral agent was able to cross the placenta by inoculation into rabbits and action of antibodies in preventing infection (Schatzmayr \& Cabral 2012).

The eradication of the disease in the Americas in 1950 occurred by the World Health Organization (WHO) and eight years after began the worldwide program to become real only in 1967 under the supervision of Dr. Henderson using vaccines with the smallpox. In 1980, WHO certified that smallpox had been eradicated.

However, the bioterrorism is discussed extensively as a global concern since there is the possibility of smallpox be used as a biological arm. Under caution, public authorities recommended laboratories to discard its viral samples, allowing only two laboratories with biosafety level 4, including the Centers for Disease Control and Prevention in the United States, which holds the virus samples for storage on the grounds of the development of new antiviral drugs and other laboratory in Russia where live virus samples are kept (Schatzmayr \& Barth 2013).

Presently, the vaccine is produced on a large scale in cell culture (Miranda, 2002) and the material samples of vesicles, pustules and crusts of patients and animals supposedly infected can be analyzed at the electron microscope to an laboratory quick diagnosis of pox viruses (Schatzmayr \& Barth 2013).

\section{Ebolavirus DiSEASE}

The virus was first discovered in 1976 near the Ebola River in what is now the Democratic Republic of the Congo. .Researchers believe that the virus is animal-borne and that bats are the most likely reservoir. Ebola is caused by Ebola virus of the family Filoviridae, genus Ebolavirus. There are five identified Ebola virus species, four of which are known to cause disease in humans: Ebola virus (Zaire ebolavirus); Sudan virus (Sudan ebolavirus); Taï Forest virus (Taï Forest ebolavirus, formerly Côte d'Ivoire ebolavirus); and Bundibugyo virus (Bundibugyo ebolavirus). The fifth, Reston virus (Reston ebolavirus), has caused disease in nonhuman primates (monkeys, gorillas, and chimpanzees), but not in humans (CDC 2016).

The transmission of virus can occur through direct contact (skin or mucous) with blood or body fluids of a person infected and through indirect contact with objects (like needles and syringes) contaminated, and by animals like fruit bats or primates infected by virus. The sexual transmission also is possibly also by the presence of virus inside the semen.

Since March 2014, West Africa has experienced the largest outbreak of Ebola in history, with multiple countries affected. But, recently on March 16, many cases of Ebola virus infection, has killed five members of the same family in Guinea, Africa, confirmed by laboratorial assay, as one case in Italy, United Kingdom, Spain and Senegal, four cases in United States, seven cases in Mali and 19 cases in Nigeria.

From a total of 3809 suspected cases in Guinea, 3353 were confirmed by infection of the Ebola virus which in 2540 cases led to death. After two incubation periods totaling 42 days, WHO declared in December 2015, Guinea a country free of the transmission of Ebola virus. The number is alarming in Sierra Leone where from a total of 14124 suspected cases, 8706 were confirmed killing 3956 people (CDC 2016).

\section{ZIKAVIRUS DISEASE}

\subsection{Taxonomy}

The Zika virus is a Flavivirus, genus of Flaviviridade family, including more than 70 viruses, among them, Japanese encephalitis virus (JEV), West Nile virus (WNV), Murray Valley encephalitis virus (MVEV), dengue virus (DENV), St. Louis encephalitis virus and yellow fever virus (CDC 2016). 


\subsection{Epidemiology}

The Zika virus was first discovered in 1947 in a sentinel rhesus monkey and was named due to Zika forest in the African Republic of Uganda. The first human cases were detected in 1952. Than the Zika outbreaks have been reported in tropical Africa, Southeast Asia and the Pacific Islands (CDC, 2016). It is believed that the Zika virus entered at Brazil in 2013, during the World Cup of confederations receiving travelers from French Polynesia and Southeast Asia. The virus genome was sequenced from isolated in samples of Brazilian patients and the lineage of the Americas found in Brazil is 99.8\% similar to the French Polynesia lineage. Thus, it is suggested that the virus was circulating in the country before 2014 when athletes from French Polynesia, New Caledonia, Cook Islands and Island Easter, places where the ZIKV circulated the World Cup and canoeing world championships held in August at Rio de Janeiro attended (Musso 2015).

\subsection{Clinical Signs}

Among the symptoms of Zika disease are: fever, joint pain, rash and conjunctivitis (red eyes). Other common symptoms include muscle pain and headache. Once Zika symptoms are similar to other arboviruses, in many cases it may not have been detected. It is important to note that most cases are asymptomatic. Once a person was bitten, go to be protected from future infection (CDC 2016).

\subsection{Transmission}

The Zika virus is transmitted through the bit of infected Aedes (A. aegypti and A. albopictus) mosquitoes. These vectors spread the dengue viruses and chikungunya virus also. The risk of congenital Zika virus infection occurs when a pregnant woman pass the virus to the fetus. To date, there is no presence of the virus reports in breast milk. Zika as a sexually transmitted disease was confirmed by the presence of the virus in the semen of infected men transmiting to their sexual partners (MUSSO et al. 2015). Several reports of transmission of blood transfusion were reported in Brazil (CDC 2016). Phylogenetic analysis of Brazilian sequences described the first case of autoctone transmission of Zika virus in Brazil (Zanluca et al. 2015) and Pan American Health Organization (PAHO) confirmed that the autoctone circulated in 18 Brazilian states.

\subsection{Diagnostic}

The viral RNA genome has been detected by molecular biology using reverse transcription of polymerase chain reaction (RT-PCR) in samples of amniotic fluid, blood and tissues (brain, liver, spleen, kidney, lung, and heart), in addition in samples of saliva, urine and semen. The virus presence was detected in the brains of infants with microcephaly showing evidence of association with the Zika virus (CDC 2016). Several research networks on Zika virus has been formulated as a task force in order to stop the viral infection. Studies have been conducted in serological tests can detect in blood samples from mothers and babies microcephalic the presence of specific antibodies against Zika virus. Accordingly, serologic assay (Enzyme-Linked Immunosorbent Assay) was developed from the recombinant NS1 protein Zika virus with the use of Escherichia coli genetically modified bacteria. As well, molecular tests such as real-time PCR are used to detect viral RNA in the first five days of infection using body fluid samples. In May 2015, the PAHO issued a warning on the first infections of Zika virus confirmed in Brazil. On February 1, 2016, the WHO declared a public health emergency of international concern. To date, no cases of Zika virus transmitted by local mosquitoes in North American states was not diagnosed, but there have been cases associated with traveling from countries presenting cases of Zika virus infection (CDC 2016).

\subsection{Neurological Syndrome}

The Brazilian Ministry of Health confirmed a relationship between Zika virus infection and the occurrence of microcephaly (brain malformation affecting babies at birth) when it became a notifiable disease. The PAHO alerts to the increased demand of possible new cases with special care for the prenatal care period and specialized care for neurological syndromes in health units. Including neurological disorders, the hypothesis of a causal relationship by Zika virus presence with the Guillain-Barré syndrome, causing muscle paralysis with special attention to respiratory muscles can lead to death (PAHO 2015).

\subsection{Prevention}

Until the date, there is no vaccine against the Zika virus and no specific antiviral treatment. DNA vaccine called pcTPANS1 against the dengue virus NS1 protein (N-linked glycoprotein conserved) induces the production of antibodies and activation of CD4 + lymphocytes acting in the defense 
mechanisms to attack the infected cells tested in animal models (Goncalves et al. 2015), target studies for flavivirus infections. The primary preventive measure has been the application of repellent icaridine base (acid-1 piperidinecarboxílico, 2- (2-hydroxyethyl) - 1-metilpropilester), DEET (N, Ndiethyl-3-methylbenzamide) and IR 3535 (3- [N-butyl-Nacetyl] aminopropionic acid ethyl-ester) recommended by Anvisa and WHO.

\section{HistoriCAL PERSPECTIVE OF THE OTHERS ARBOVIRUSES}

Many Americans departments as centers for disease control and prevention, and division of vectorborne diseases are on alert with the arrival of the Olympic and Paralympic Games, which will take place from 5 to 21 August 2016 and 7 to 18 September 2016, in the city of Rio de Janeiro, Brazil, that may facilitate the entry of new viruses in the country (CDC, 2016). Arboviruses are also the subject of studies by researchers around the world, such as O`nyong-Nyong virus, Wesselsbron virus, Rift Valley fever Virus and Usutu virus, to be addressed in sequence.

\subsection{O'nyong-Nyong Virus (ONNV)}

The O'nyong-Nyong virus (ONNV) belong to the Togaviridae family, Alphavirus genus and was first isolated in 1959 from human and mosquito blood in Gulu, Uganda. The virus was isolated from mononuclear cells of the peripheral blood of a French soldier, 19 years old, on mission in Chad, north central Africa, who presented antibodies (seroconversion) for a serologically related virus CHIKV (IgM and IgG). The viral RNA was amplified using NSP3 E2 and E1 sequences of the specific primers for ONNV. RT-PCR products were sequenced and aligned with the sequences available at Gen Bank and the cases diagnosis of ONNV was confirmed (Bessaud 2006, CDC 2016).

\subsection{Wesselsbron Virus}

Another flavivirus of the Flaviviridade family is the Wesselsbron virus, etiologic agent of Wesselsbron disease, also an arbovirus firstly described in 1955 in sheep in Wesselsbron district in South Africa. The virus was isolated in 1989 for the first time in Madagascar from Aedes including A. caballus and A. circumluteolus (Mushi et al. 1998, CDC 2016, Wesselsbron 2007). Serological studies in man have been investigated by haemagglutination inhibition assay (Morvan et al.1990).

\subsection{Rift Valley Fever Virus (RVFV)}

Rift Valley fever virus (RVFV) is a member of the genus Phlebovirus, the Bunyaviridae family, responsible for Rift Valley fever (RVF) reported in cattle in Kenya Rift Valley at Kenya, África, early 1910s (CDC, 2016). However, the isolation of the virus was conducted only in 1931 during an epidemiological investigation among sheeps at Kenya. The Rift Valley fever virus is also another concern of public health. Transmitted by Aedes and Culex mosquitoes, it is responsible for encephalitis, haemorrhagic fevers and retinal lesions in humans. It had been recorded of cases in subSaharan Africa and the Middle East (Anyamba et al. 2001).

Geological and climatic conditions of the ecosystem influence for the spread of the virus and its interactions between animals and humans, as occurred in 1987 in West Africa. Humans can be infected with RVFV through the bite of infected mosquitoes. However, humans are infected also after exposure to blood, body fluids or tissues of animals infected with the virus. Infection by aerosol transmission of RVFV has occurred in the laboratory environment (CDC 2016).

\subsection{Usutu Virus (USUV)}

The Usutu virus (USUV) is a flavivirus transmitted by mosquitoes and is closely related to Japanese encephalitis virus (JEV), Murray Valley encephalitis virus (MVEV) and West Nile virus (WNV). In 1959, USUV was isolated from Culex mosquitoes in South Africa. It was described in 2001 in Austria circulating for the first time in Europe. The first two human cases of infection were recorded in Italy in 2009 causing meningoencephalitis in immunocompromised patients. Various cell lines can be infected to investigate the USUV, in particular VERO cells, PK-15 cells and goose embryo fibroblasts able to develop cytopathic effects of the virus. Previous studies showed demyelination areas of neurons (Ashraf et al. 2015, CDC 2016).

\section{Puerperal FeVer disease}

Puerperal fever epidemic is a classic example of an epidemiological research. In the nineteenth century, Ignaz Semmelweis, an Hungarian obstetrician, suspected of possible etiologies and causal 
mechanism of puerperal fever from the clinical observation of an epidemic that decimated the pregnant women. An increasing of the number of mothers and children who died of this disease was observed at the Vienna maternity since 1840 . Motherhood was divided into two clinics. The first clinic received only resident obstetricians for training, and the second clinic only midwife. It was found that the death rate was distinctly different between the two clinics (Bonita et al. 2010, Gordis 2010, Semmelweis 2016).

In 1846, the prevailing opinion was that the disease stemmed from injuries resulting from the birth canal due to gynecological examinations. As the tests were also done by midwives, they believed that students often foreign men were responsible for the contamination. As a result of speculation, the number of students was reduced from 42 to 20 . There was a marked reduction in mortality during the period of absence of foreign students which was justified by the fact that they normally attend various services during his probationary period and thus assist more autopsies being more exposed to contaminants, or by the coincidence with the removal of Semmelweis's recomendations in that time (Potter 2001, Gordis 2010).

In March 1847, the death of the doctor and Professor of Forensic Medicine, Jakob Kolletschka, admired by Semmelweis, led him to a new and critical reasoning about the cause of puerperal fever. Autopsies, for lawful purposes, carried out by Prof. Kolletschka were always assisted by students. On one occasion, a student accidentally pierced the finger of the Prof. Kolletschka with the same blade used at autopsy. The disease that caused the professor's death was, to Semmelweis, identical to what had induced the death of hundreds of patients at the hospital. Just as the lesions found in newborns, Semmelweis concluded that these died from puerperal fever, and the lesions found in the teacher's autopsy was based in the same critical thinking also (Potter, 2001; Bonita et al. 2010, Gordis 2010, Semmelweis 2016).

The cause of his illness was the penetration of cadaver particles in the injury and the cut with a scalpel, leading him to believe that, these particles also penetrated in the women of the maternity who died of puerperal fever. A hypothesis was that these particles were adhered to the scalpel, and could also have adhered hands of the students that examined pregnant women. In May 1847, it was implemented as a preventive practice, that after autopsy and before exams of pregnant women the hands should be watered using chlorinated water. After seven months of basic hygiene intervention, the first clinical mortality rates, reduced below the levels of the second clinic. At the time, there was resistance among students and teachers to adopt the disinfection method (Bonita et al. 2010, Gordis 2010).

After hand washes with chlorinated water to remove infectious particles within the range of an examination and another, hand washing with only soap and water was enough. However, even with hand washing after examining a woman with cervical carcinoma associated with intense purulent discharge, succeeded eleven deaths of twelve women examined later.

In November 1847, new preventive measures transferring patients to isolation rooms have been adopted after the mother's care suffering from suppurative processes determining tightening in hand disinfection process. Thus, the application of new preventive methods succeeded in higher mortality rates in the second clinical (1.33\%) when compared to the first (1.27\%) in 1948.

After Semmelweis was fired in 1849, he managed to enter his measurements and control actions at the hospital in Budapest, Hungary and also obtained a reduction of mortality rates. It was its main objective the dissemination of its prophylactic method in other hospitals.

After his death in 1865 at 47 years old, the aseptic precautions in obstetric care were intensified despite not having the scientific recognition of his work, which was heavily criticized and persecuted (Gordis 2010). Accepting his hypothesis, it was directly proportional to the idea that doctors themselves were responsible for the deaths of their patients who did not admit that fact.

The Public Health Service in 1961 performed a film with handwashing techniques. The Centers for Disease Control and Prevention published a guideline for hand hygiene in hospitals in 1975 and 1985. In the next years, serious guidelines for hand antisepsis will be published to infection control (CDC 2002).

\section{Cholera disease}

Another example of epidemiological observations in public policy occurred in 1854 in London where about 600 people came to death for suspected disease transmitted through contaminated water by the 
Tâmisa river. At that time John Snow, anesthetist, based on frequency components and distribution of diseases, and in the case of formulation on the etiology, made the epidemiology of shoe leather, going from house to house counting cholera deaths in each of them and determining which supply company provided water in every house (Gordis 2010).

Snow postulated that the transmission of cholera caused by the bacteria Vibrio cholera was given by contaminated water through an unknown mechanism. He noted that death rates were particularly high in the areas supplied by the Lambeth or Southwark \& Vauxhall Water Company both drained the water of the Tâmisa river in the polluted site for waste. Snow was able to formulate and test the hypothesis that drinking water provided by the Southwark \& Vauxhall companies increased the risk of contracting cholera in comparison to the Lambeth Company (Gordis 2010).

About 315 cholera deaths were found for 10,000 houses supplied by Southwark \& Vauxhall Company, while 38 deaths were observed in houses supplied by the Lambeth Company. This company had transferred its uptake of water to above the Tâmisa River which was a less polluted area. Thus, John Snow was able to prove his hypothesis. This was the first natural experiment based on the epidemiological reasoning and research method that has been documented in his book "On the Mode of Communication of Cholera" and is referenced to this day (Snow 2011).

The gold standard for the laboratory diagnosis of cholera is the isolation and identification of Vibrio cholera serogroup O1 or O139 by culture of a stool (CDC 2016). Since 2005, cholera cases have increased and the disease still occurs in many places including Africa, Southeast Asia, Haiti and Brazil but is rare in the United States (CDC 2016).

\section{Conclusions}

Even with all the technological advances of medicine and research methods, today we observe failures of patients care without basic health care, a simple act of washing hands. The emergence and reemergence of new diseases reappear in the clinical area and sometimes awakens to a new panorama of an unknown disease.

From the XXth century, an epidemiological transition time/period, there was a predominance of noninfectious diseases classified as chronic degenerative replacing infectious diseases.

The epidemiology of the XXIth century emphasizes the risk factors relating the styles of individual life versus population determinants drawing a parallel between the balance and interaction between the research at the macro level addressing the population as a whole, individually characterized by own lifestyle, and the micro level referring genetic characteristics permeating epigenetic studied extensively in modern times.

Epidemics in the past such as smallpox, yellow fever, influenza and polio are still investigated by the experts in the field of virology and molecular epidemiology to vaccine production associated with prevention statistics of population.

Regardless of the time or medical condition, the objective of epidemiological research is based on the description of the facts, the elucidation of health determinants and to test hypothesis to propose measures of preventive actions in public health. Such investigations act together with multidisciplinary professional groups such as epidemiologists, virologists, immunologists and clinicians to discover the silent challenges that the human population is exposed.

\section{ACKNOWLEDGEMENT}

A research fellowship was obtained by the first author from the Coordenação de Aperfeiçoamento de Pessoal de Nível Superior (Capes) and by the second author from the Conselho Nacional de Desenvolvimento Científico e Tecnológico (CNPq).

\section{REFERENCES}

Anyamba A, Linthicum KJ, Tucker CJ 2001. Climate-disease connections: Rift Valley Fever in Kenya. Cad. Saúde Pública, Rio de Janeiro, 17:133-140.

Argyri E, Papaspyridakos S, Tsimplaki E, Michala L, Myriokefalitaki E, Papassideri I, Daskalopoulou D, Tsiaoussi I, Magiakos G, Panotopoulou, E 2013. A cross sectional study of HPV type prevalence according to age and cytology. BMC Infectious Diseases, 13:53.

Ashraf U, Ye J, Ruan X, Wan S, Zhu B, Cao S 2015. Usutu virus: an emerging flavivirus in Europe. Viruses. 19;7(1):219-38. doi: 10.3390/v7010219. 
Bessaud M, Peyrefitte CN, Pastorino BAM, Gravier P, Tock F, Boete F, Tolou HJ, Grandadam M 2006. O'nyong-nyong Virus, Chad. Emerg Infect Dis. 12(8): 1248-1250.

Bonita R, Beaglehole R, Kjellström T 2010. Epidemiologia Básica, 2.ed. Santos Editora:World Health Organization: São Paulo, 230p.

Clarke MA, Rodriguez AC, Gage JC, Herrero R, Hildesheim A, Wacholder S, Burk R, Schiffman MA 2012. Large, population-based study of age-related associations between vaginal $\mathrm{pH}$ and human papillomavirus infection. BioMed Central Infectious Diseases, 12:33.

Figueiredo-Alves RR, Turchi MD, Santos LE, Guimaraes EMB, Garcia MMD, Seixas MSC, Villa LL, Costa MC, Moreira MAR, Alves MFC. 2013. Prevalence, genotype profile and risk factors for multiple human papillomavirus cervical infection in unimmunized female adolescents in Goiania, Brazil: a community-based study. BMC Public Health, 13:1041.

Gonçalves AJS, Oliveira RRA, Costa SM, Paes MV, Silva JFA, Azevedo AS, Mantuano-Barradas M, Nogueira ACMA, Almeida CJ, Alves AMB 2015. Cooperation between CD4+ T Cells and Humoral Immunity Is Critical for Protection against Dengue Using a DNA Vaccine Based on the NS1 Antigen. PLOS Neglected Tropical Diseases | DOI:10.1371/journal.pntd.0004277 December 9, 1:22, 2015

Gordis L 2010. Epidemiologia. 4 ed, Revinter: Rio de Janeiro, p.372.

Kavanagh K, Sinka, K, Cuschieri K, Love J, Potts A, Pollock KG, CubieH, Donaghy M, Roberston C 2013.Estimation of HPV prevalence in Young women in Scotland; monitoring of furure vaccine impact. BioMed Central Infectious Diseases, 13:519.

Last J 1988. A Dictionary of Epidemiology, 2nd ed. New York, Oxford University Press.

Medronho R, Bloch KV, Luiz RR, Werneck GL 2009. Epidemiologia. $2 a$ ed. São Paulo: Atheneu. p.673.

Miranda, MMFS 2002. História da Virologia. In: Introdução à virologia humana. Ed(s): Santos, Norma Suely de Oliveira; Romanos, Maria Teresa Villlela; Wigg, Márcia Dutra. Guanabara Koogan: Rio de Janeiro, p.1-10.

Morvan J,Fontenille D, Digoutte JP, Coulanges P 1990. The Wesselsbron virus, a new arbovirus for Madagascar. Arch Inst Pasteur Madagascar. 57(1):183-92.

Mushi EZ, Binta MG, Raborokgwe M 1998. Wesselsbron disease virus associated with abortions in goats in Botswana. J Vet Diagn Invest 10:191.

Musso D, Roche C, Robin E, Nhan T, Teissier A, Caolormeau V-M 2015. Potential sexual transmission of Zika virus. Emerging infectious diseases, 21 (2): 359-360.

Musso D. Zika vírus: from French Polynesia to Brazil 2015. Emerging Infectious Diseases, 21 (10): 1887

Pan American Health Organization (PAHO) 2015. Epidemiological Alert. Neurological syndrome, congenital malformations and Zika virus infections. Implications for public health in the Americas, 11p.

Panatto D, Amicizia D, Tanzi E, Bianchi S, Frati ER, Zotti CM, Lai PL, Bechini A, Rossi S, Gasparini R 2013. Prevalence of human papillomavirus in young Italian women with normal cytology: how should we adapt the national vaccination policy? BioMed Central Infectious Diseases, 13:575.

Pereira CRN, Rosa MLG, Vasconcelos GALBM, Faria PCP, Cavalcanti SMB, Oliveira LHS 2007. Human papillomavirus prevalence and predictors for cervical cancer among high-risk women from Rio de Janeiro, Brazil. International Journal Gynecology Cancer, 17: 651-660.

Potter P 2001. About the Cover: Ignaz Philipp Semmelweis (1818-65). Emerging Infectious Diseases, 7(2), March-April.

Schatzmayr H, Barth OM 2013. Bioterrorismo e microrganismos patogênicos. História, Ciências, Saúde - Manguinhos, Rio de Janeiro. 20(4):735-1749.

Schatzmayr H, Cabral M 2012. A virologia no Estado do Rio de Janeiro - uma visão global, 2. Ed., Fiocruz, Ministério da Saúde.

Semmelwies, I.P. Historical Moments. Part I: Public Health, Passion and Persistense. Jones and Bartlett Publishers, p. 1-12. Available at: http://www.jblearning.com/ samples/ 0763738786/ 38786_PT01_001_012.pdf. Accessed April 4, 2016. 
Simões RSQ, Barth OM 2015.Papillomavirus: Viral vectors in the gene therapy and new therapeutic targets. International Journal of Biomedical Research 2015; 6(10): 763-768.

Snow, J. John Churchill, London: Princes Street, Soho. Available at: http://www.ph.ucla.edu/epi/ snow.html, Accessed November 13, 2011.

United States Centers for Disease Control and Prevention (CDC) 2002. Morbidity and mortality weekly report, 51:1-56.

United States Centers for Disease Control and Prevention (CDC) Available at: http://www.cdc.gov /vhf/rvf/index.html, accessed March 27, 2016.

United States Centers for Disease Control and Prevention (CDC) Available at: http://www.cdc.gov/ zika, accessed March 27,2016.

United States Centers for Disease Control and Prevention (CDC) Available at: http://www.cdc.gov/ vhf/ebola, accessed March 28,2016.

Wesselsbron Disease. 2007. Available at: http://www.cfsph.iastate.edu/ Factsheets/pdfs/ wesselsbron.pdf, accessed April 11, 2016.

UusKula A, Muursepp A, Kawai K, Raag M, Jurisson M, Pillsbury M 2013. The epidemiological and economic impact of a quadrivalent human papillomavirus (HPV) vaccine in Estonia. BioMed Central Infectious Diseases, 13:304.

Zanluca C, Melo VCA, Mosimann ALP, Santos GIV, Santos CND, Luz K 2015. First report of autochthonous transmission of Zika virus in Brazil. Memórias do Instituto Oswaldo Cruz, 110(4): 569-572. 